\title{
A Decision Support Methodology to Enhance the Competitiveness of the Turkish
} Automotive Industry

Füsun Ülengin ${ }^{\mathrm{a}}$, Şule Önsel ${ }^{\mathrm{b}}$, Emel Aktas $^{\mathrm{c}}$, Özgür Kabak ${ }^{\mathrm{d}}$ and Özay Özaydın ${ }^{\mathrm{b}}$

${ }^{a}$ Corresponding author, Sabancı University, School of Management, Orta Mahalle, Tuzla,

34956 Istanbul, Turkey, fulengin@gmail.com, Tel.:+90 216483 9656; fax:+90 2164839699

${ }^{\mathbf{b}}$ Industrial Engineering Department, Dogus University, Acibadem Zeamet Sok, 34722,

Istanbul, Turkey \{ sonsel, ozaydin\}@dogus.edu.tr

${ }^{\mathbf{c}}$ Business School, Brunel University, Kingston Lane, Uxbridge, UB8 3PH, UK, emel.aktas@brunel.ac.uk

d Industrial Engineering Department, Istanbul Technical University, Macka 34367, Istanbul, Turkey, kabak@itu.edu.tr

\begin{abstract}
Three levels of competitiveness affect the success of business enterprises in a globally competitive environment: the competitiveness of the company, the competitiveness of the industry in which the company operates and the competitiveness of the country where the business is located. This study analyses the competitiveness of the automotive industry in association with the national competitiveness perspective using a methodology based on
\end{abstract} Bayesian Causal Networks. First, we structure the competitiveness problem of the automotive industry through a synthesis of expert knowledge in the light of the World Economic Forum's competitiveness indicators. Second, we model the relationships among the variables identified in the problem structuring stage and analyse these relationships using a Bayesian Causal Network. Third, we develop policy suggestions under various scenarios to enhance the national competitive advantages of the automotive industry. We present an analysis of the Turkish automotive industry as a case study. It is possible to generalise the policy suggestions developed for the case of Turkish automotive industry to the automotive industries in other developing countries where country and industry competitiveness levels are similar to those of Turkey.

Keywords: Decision support systems; Bayesian causal network; Competitiveness; Automotive industry; Turkey. 


\section{Introduction}

In a globalised world, both developed and developing countries compete at an international level. For policy makers in general, one of the most significant issues is making their economies competitive and coping with global risks through rational policies.

The automotive industry is a key contributor to the national economy, particularly for industrialised countries. As the primary customer, the automotive industry motivates technical development in the iron-steel, petrochemical and tire industries. The automotive industry produces all types of motor vehicles needed for tourism, infrastructure maintenance, transportation and agriculture. Therefore, any changes in the automotive industry deeply affect the entire economy. The global automotive industry produces approximately 70 million units each year, playing a vital role in the world economy and making important contributions to the well-being of societies (Ulengin et al., 2010). Enhancing the competitiveness of the automotive industry is of crucial importance for both developed as well as emerging economies such as China (EC, 2012; Lin \& Wu, 2011).

The success of a specific industry in a country depends strongly on the national competitiveness of that country (Porter, 1990). Thus, the institutions, the infrastructure, the macroeconomic environment and the facilities for health care and primary education greatly affect the competitiveness of a nation's industries (Sala-i-Martin, 2012). For instance, a welldeveloped transportation infrastructure and communication network may be a prerequisite for having access to core economic services and activities. Therefore, the infrastructure is highly likely to influence the success of a specific industry. Additionally, because the macroeconomic environment influences the related microeconomic and firm-level operational conditions, it plays an important role in the success of any industry (Choi \& Jeon, 2011).

Business investment is also critical to productivity. Therefore, economies with sophisticated financial markets can make capital available for private-sector investments (Sala-i-Martin, 2012). By this logic, it is also possible to demonstrate that the level of the primary and higher education, the labour market efficiency and the financial market development influence the industrial competitiveness in a country. Consequently, there is a strong link between the competitiveness of a country and the competitiveness of its industries. This linkage necessitates development of a framework for decision making to analyse these links and to identify policies to support industries that face major foreign competitors.

In the automotive industry, this type of policy analysis is performed using a SWOT (Strengths, Weaknesses, Opportunities and Threats) analysis (EC, 2006; TRMSIT; 2012) or PESTLE (Political, Economic, Social, Technological, Legal and Environmental) analysis 
(Niewenhuis \& Wells, 2003). However, a SWOT analysis highlights only the principle concepts and does not provide a holistic perspective on the interrelationships among all factors. It is therefore not possible, for example, to specify the level of the improvement that can occur when a certain policy is followed to reduce a given threat. Similarly, it is not possible to estimate the value of all the related variables that are included in the analysis. For this reason, Bayesian Causal Networks (BCNs), which allow the modelling and the analysis of interdependent causal relationships, are used in this study. BCNs are probabilistic inference engines that enable analysts to answer queries or perform what-if analyses about the variables in a network. Using a BCN, the impact of changing the value of one or more variables on the remaining variables in the network can be analysed by estimating the values of those variables and providing the associated probabilities (Lauria \& Duchessi, 2007). However, this type of analysis cannot be conducted using SWOT-like methods.

The purpose of this study is to analyse the effects of the factors that provide a national competitive advantage to the automotive industry through a comprehensive analytical model based on BCNs. This study aims to facilitate selection and prioritisation of policies to improve the competitiveness of the automotive industry in a country. The Turkish automotive industry is selected as a case study because it is sensitive to global developments and, according to Turkish Automotive Industry Strategy Document (TEMIT, 2012) prepared by the Ministry of Industry, has an urgent need for support to benefit from post-crisis opportunities.

The primary contribution of the study is a novel three-stage methodology based on BCNs for analysing the competitiveness of the automotive industry. The use of BCNs gives direct information to decision makers in the automotive sector. The methodology is based on an analysis of all factors of the national competitiveness that influence the competitiveness of automotive industry. Because these factors and their relationships are revealed through successive workshops conducted with experts from the related field, this approach provides a credible, accessible and "owned" model. The BCN-based model is transparent to all stakeholders. This model acknowledges and describes uncertainties. To the best of our knowledge, the three-stage methodology is the first attempt to provide a structured roadmap to the policy makers for the automotive industry.

This paper is structured as follows: Section 2 provides a literature review on national, industrial and automotive industry competitiveness. Section 3 explains the proposed methodology developed for analysing the competitiveness of the automotive industry. Section 4 provides policy suggestions developed to enhance the competitiveness of the Turkish automotive industry. Finally, Section 5 presents the discussion and conclusions. 


\section{Literature Review}

National competitiveness is a measure of the relative ability of a nation to create and to maintain an environment for businesses to operate and, consequently, to improve the level of prosperity (Kao et al., 2008). The national competitiveness level is an important stimulus that shapes the international competitive position of the firms operating in that country (Artto, 1987; Oral et al., 1999). Therefore, this literature review consists of three sections, 1) national competitiveness, 2) industry competitiveness and links with national competitiveness, and 3 ) competitiveness in the automotive industry.

\subsection{National competitiveness}

Porter (1990)'s well-known "Diamond" model is one of the earliest and most frequently cited studies on the competitiveness of nations. According to this model, a nation's position in factors of production such as skilled labour or infrastructure is critical for that nation to compete in a given industry.

Several international organisations, such as the World Economic Forum (WEF) and the Institute for Management Development (IMD), have made great efforts to measure national competitiveness. These organisations apply several hundred objective and subjective indicators to assess the wealth created by the world's nations and subsequently publish rankings of national competitiveness. The IMD World Competitiveness yearbook has measured 59 countries on the basis of 329 criteria since 1989 (IMD, 2012). Since 2005, the WEF has published global competitiveness reports for more than 100 countries on the basis of over 100 criteria. These rankings serve as benchmarks for policy makers and other interested parties to judge the competitive success of their countries within a global context (WEF, 2012).

Wang et al. (2007) suggest a model that uses technology development, economic performance, human resources, and management capability to explain national competitiveness. Furthermore, Hamalainen (2003) creates an extended model that incorporates technological innovation and diffusion, international business activities, and the role of government into earlier models of national competitiveness.

Edwards and Golub (2004) use econometric models and time series to analyse the international cost competitiveness of South Africa. Their results indicate improvements in cost competitiveness but do not explain national competitiveness. Zanakis and BecerraFernandez (2005) predict the competitiveness of countries by analysing four knowledge discovery methods: 1) stepwise regression models, 2) weighted nonlinear programming models, 3 ) neural networks, and 4) classification and regression trees. According to their 
research, two independent variables have major effects on the competitiveness of a nation: international risk rating and computers per capita based on the data of 1999.

Kao et al. (2008) measure the national competitiveness of Southeast Asian countries by deconstructing their national competitiveness into four factors, economy, technology, human resources and management, and combining hard (published) and soft (expert opinions) data. These authors present suggestions to the governments of analysed countries that highlight opportunities to improve their competitiveness at the national level. These surveys show that the measurement of national competitiveness is a complicated concept because it involves many aspects of data collection and problem structuring. Similar problems are also encountered in the measurement of industry competitiveness, which is discussed in the following section.

\subsection{Industry competitiveness}

An early attempt to quantify industrial competitiveness defines the competitiveness of a manufacturer as a function of its industrial mastery, cost superiority, and political-economic environment (Oral, 1988). This model can be applied to support strategic decisions about technology selection, productivity management, or investment planning.

Lipovatz et al. (2000) consider labour productivity, vertical integration, technological innovation, and firm size to be critical factors for industrial competitiveness and apply multivariate analysis to assess these factors in the Greek food and beverage industries. They find that productivity evolution correlates primarily with organisational and structural changes and, to a lesser extent, with growth rate and technological innovations. A reduction in raw material consumption per unit product has a positive impact on labour productivity.

Liu et al. (2004) use a correlation model to study the link between knowledge management capability and competitiveness and test their model on high-tech enterprises. These authors conclude that there is a significant relationship between knowledge management capability and industrial competitiveness, but they explain competitiveness from a single perspective. Guan et al. (2006) assert that an exploration of quantitative relationships between technological innovation capability and competitiveness suggests a close internal relationship between these two variables. Similarly, Castellacci (2008) makes a comprehensive comparison of mainstream explanations and evolutionary approaches to innovation and industrial competitiveness. Their results reveal that the mainstream explanations follow a market-oriented view and economic policy, while the evolutionary approaches emphasise institutional arrangements and policy interventions. 
The competitiveness of an industry is analysed generally on the basis of a single perspective. However, a measure of industry competitiveness should cover a much broader perspective and highlight the factors that have the greatest impact on shaping the competitiveness of that industry. In fact, the relationships between such factors depend on the characteristics of the industry of interest and may differ from one industry to another.

\subsection{Competitiveness in the automotive industry}

Few studies assess the competitiveness level of the automotive industry. Evidence from the Polish automotive sector suggests that knowledge transfer from transnational corporations improves the performance of local suppliers and subsequently increases their ability to compete (Simona and Axèle, 2012). Tcha and Kuriyama (2003) analyse the effects of government policies on the Australian automotive industry using a partial equilibrium model. Those authors warn that globalisation of the world automotive market will depress prices and the expected welfare effects of government policies will depend on each country's tariff rates and manufacturing costs.

D'Costa (1988) examines competitiveness in the automotive industry in India using case studies of co-operation among firms and its relationship to market performance. The findings suggest that flexible industry-level practices, institutionalised co-operation between and within firms and teamwork are used to overcome entry barriers, respond effectively to competitors, and take advantage of new markets and technologies. In a similar study, Williamson (2001) investigates the relationship between exchange rate exposure and competition in the automotive industry. Evidence supports theoretical determinants of foreign exchange rate exposure for firms in the globally competitive automotive industry.

Sirikrai and Tang (2006) suggest a four-level Analytical Hierarchy Process (AHP) model to analyse the competitiveness of the automotive components industry in Thailand and compare sub-elements of competitive conditions, government roles, managerial resources, and technological capabilities. However it is unable to capture the interactions between variables in the model. A comparable study by Laosirihongthong and Dangayach (2005) empirically analyses the implementation of manufacturing strategies in Thai and Indian automotive manufacturing companies. In those two countries, companies focus on the improvement of product and process-related quality and on-time delivery.

A related study of Korean and Malaysian automotive supplier industries reveals that upper-tier suppliers need to operate in global value chains (Wad, 2008). For Korean and Malaysian automotive manufacturers, competitiveness depends on their alliance with foreign automobile suppliers, modularisation, and national automotive policies and institutions. In 
their case study of the South African automotive industry, Barnes and Morris (2008) conclude that the automotive sector in a developing country needs to continuously upgrade performance, skills, and technology to remain within the global automotive value chains.

The summary of the literature review presented in the above three subsections shows that the indicators and drivers of competitiveness are multi-faceted with complex relationships (see Table 1). Therefore, one or several aspects will not be sufficient to explain competitiveness thoroughly at the industrial or national level.

Table 1 shows that in global competition, the roles of the technological infrastructure, the education system, public-private sector relations, and economic policies are integrated. For businesses attempting to gain a competitive advantage, their success depends on their ability to perceive and adapt to short-term changes. The competitiveness level of the industry relates closely to national global competitiveness levels. Budd and Hirmis (2004) discuss the relationships among firm competition, industry competitiveness and national competitiveness.

In the literature, the link between industry competitiveness and national competitiveness appears only for a few specific indicators of global competitiveness, but this paper takes a comprehensive holistic approach to explain industry level competitiveness in terms of all factors constituting country-level competitiveness. The automotive industry is selected, in particular, to show this link. The proposed methodology aims to guide decision makers in determining and measuring the competitiveness of the automotive industry as well as developing appropriate strategies to improve its competitiveness level. 
Table 1 National, industrial and automotive competitiveness literature

\begin{tabular}{|c|c|c|c|}
\hline Authors & Scope & Determinants of competitive advantage & Method \\
\hline $\begin{array}{l}\text { Porter (1990) (Porter's } \\
\text { diamond) }\end{array}$ & National & $\begin{array}{l}\text { Factor conditions } \\
\text { Firm strategy, structure, and rivalry } \\
\text { Demand conditions } \\
\text { Related and supporting industries }\end{array}$ & $\begin{array}{l}\text { A four-year study of ten important trading } \\
\text { nations; comprehensive analysis of industries } \\
\text { based on statistical data and historical } \\
\text { examinations }\end{array}$ \\
\hline Dunning (1992) & National & $\begin{array}{l}\text { Porter's diamond } \\
\text { Transnational business activity } \\
\text { Government } \\
\text { Chance }\end{array}$ & Literature review \\
\hline Roessner et al. (1996) & National & $\begin{array}{l}\text { National orientation } \\
\text { Socio-economic infrastructure } \\
\text { Technological infrastructure } \\
\text { Productive capacity }\end{array}$ & Statistical analysis of expert opinion survey \\
\hline Hamalainen (2003) & National & $\begin{array}{l}\text { Productive resources } \\
\text { Technological innovation and diffusion } \\
\text { Organisational efficiency } \\
\text { Product market characteristics } \\
\text { International business activities } \\
\text { Institutional framework } \\
\text { Government role }\end{array}$ & Econometric models of empirical data \\
\hline Edwards and Golub (2004) & National & Relative unit labour costs & Time series analysis \\
\hline $\begin{array}{l}\text { Zanakis and Becerra- } \\
\text { Fernandez (2006) }\end{array}$ & National & $\begin{array}{l}\text { International country risk rating and computers per } \\
\text { capita }\end{array}$ & $\begin{array}{l}\text { Stepwise regression models, weighted } \\
\text { nonlinear programming models, neural } \\
\text { networks, and classification and regression } \\
\text { trees }\end{array}$ \\
\hline Wang et al. (2007) & National & $\begin{array}{l}\text { Technology development } \\
\text { Economic performance } \\
\text { Human resources } \\
\text { Management capability }\end{array}$ & $\begin{array}{l}\text { Statistical analysis of official publications and } \\
\text { expert opinions }\end{array}$ \\
\hline
\end{tabular}




\begin{tabular}{|c|c|c|c|}
\hline Authors & Scope & Determinants of competitive advantage & Method \\
\hline$\overline{\text { Kao et al. (2008) }}$ & National & $\begin{array}{l}\text { Economy } \\
\text { Technology } \\
\text { Human resource } \\
\text { Management }\end{array}$ & $\begin{array}{l}\text { Hard (databases) and soft (expert opinions) } \\
\text { data }\end{array}$ \\
\hline Oral and Reisman (1988) & Industrial & $\begin{array}{l}\text { Industrial Mastery } \\
\text { Cost Superiority } \\
\text { Political-Economic Environment }\end{array}$ & $\begin{array}{l}\text { Qualitative and quantitative data analysis of } \\
\text { surveys, interviews and empirical data }\end{array}$ \\
\hline Lipovatz et al. (2000) & Industrial & $\begin{array}{l}\text { Labour productivity } \\
\text { Vertical integration } \\
\text { Technological innovation } \\
\text { Size of enterprises }\end{array}$ & $\begin{array}{l}\text { Multivariate analysis (principal component } \\
\text { analysis and canonical analysis) }\end{array}$ \\
\hline Liu et al. (2004) & Industrial & $\begin{array}{l}\text { Enterprise status } \\
\text { Knowledge management capability }\end{array}$ & Statistical analysis of survey data \\
\hline Guan et al. (2006) & Industrial & $\begin{array}{l}\text { Learning } \\
\text { R\&D } \\
\text { Manufacturing } \\
\text { Marketing } \\
\text { Organising } \\
\text { Resource } \\
\text { Market share } \\
\text { Sales Growth } \\
\text { Export rate } \\
\text { Profit growth } \\
\text { Productivity } \\
\text { New product rate }\end{array}$ & Data envelopment analysis of survey data \\
\hline Castellacci (2008) & Industrial & $\begin{array}{l}\text { Innovation } \\
\text { Intersectoral diffusion of advanced knowledge }\end{array}$ & $\begin{array}{l}\text { Comparison of mainstream and evolutionary } \\
\text { views in terms of their theoretical foundations, } \\
\text { empirical research and policy implications. }\end{array}$ \\
\hline
\end{tabular}




\begin{tabular}{llll}
\hline Authors & Scope & Determinants of competitive advantage & Method \\
\hline D'Costa (1998) & Automotive & $\begin{array}{l}\text { Flexibility } \\
\text { Teamwork } \\
\text { Institutionalised cooperation } \\
\text { Industrial technology }\end{array}$ & Case study \\
& & Exchange rate exposure & Econometric models \\
\hline Williamson (2001) & Automotive & Government policies & Sconometric models \\
\hline Tcha and Kuriyama (2003) & Automotive & Quality, Delivery, Flexibility, Cost & Inferential Statistics \\
\hline Laosirihongthong and & Automotive & AHP based analysis of automotive \\
Dangayach (2005) & Automotive & $\begin{array}{l}\text { Industrial competitive conditions } \\
\text { Governmental Roles } \\
\text { Sirikrai and Tang (2006) }\end{array}$ & Managerial resources \\
& & Technology capabilities & componts industry competitiveness \\
\hline Barnes and Morris (2008) & Automotive & $\begin{array}{l}\text { Key integrating technologies } \\
\text { Intelligently designed selective policies }\end{array}$ & $\begin{array}{l}\text { Case study on South Africa automotive } \\
\text { industry }\end{array}$ \\
\hline Wad (2008) & Automotive & Modularisation & $\begin{array}{l}\text { Analysis of the local and global automobile } \\
\text { industries with a global value chain } \\
\text { perspective }\end{array}$ \\
\hline Simona and Axèle (2011) & Automotive & Knowledge transfer & Survey, Inferential Statistics \\
\hline
\end{tabular}




\section{Proposed Methodology}

This study aims to analyse the effects of the factors that enable a national competitive advantage in establishing a competitive superiority in the automotive industry and particularly in the Turkish Automotive industry. For this purpose, we propose a three-stage methodology: problem structuring, causal modelling and analysis (Figure 1). To explain each stage, we follow an input - process - output approach in Figure 1.

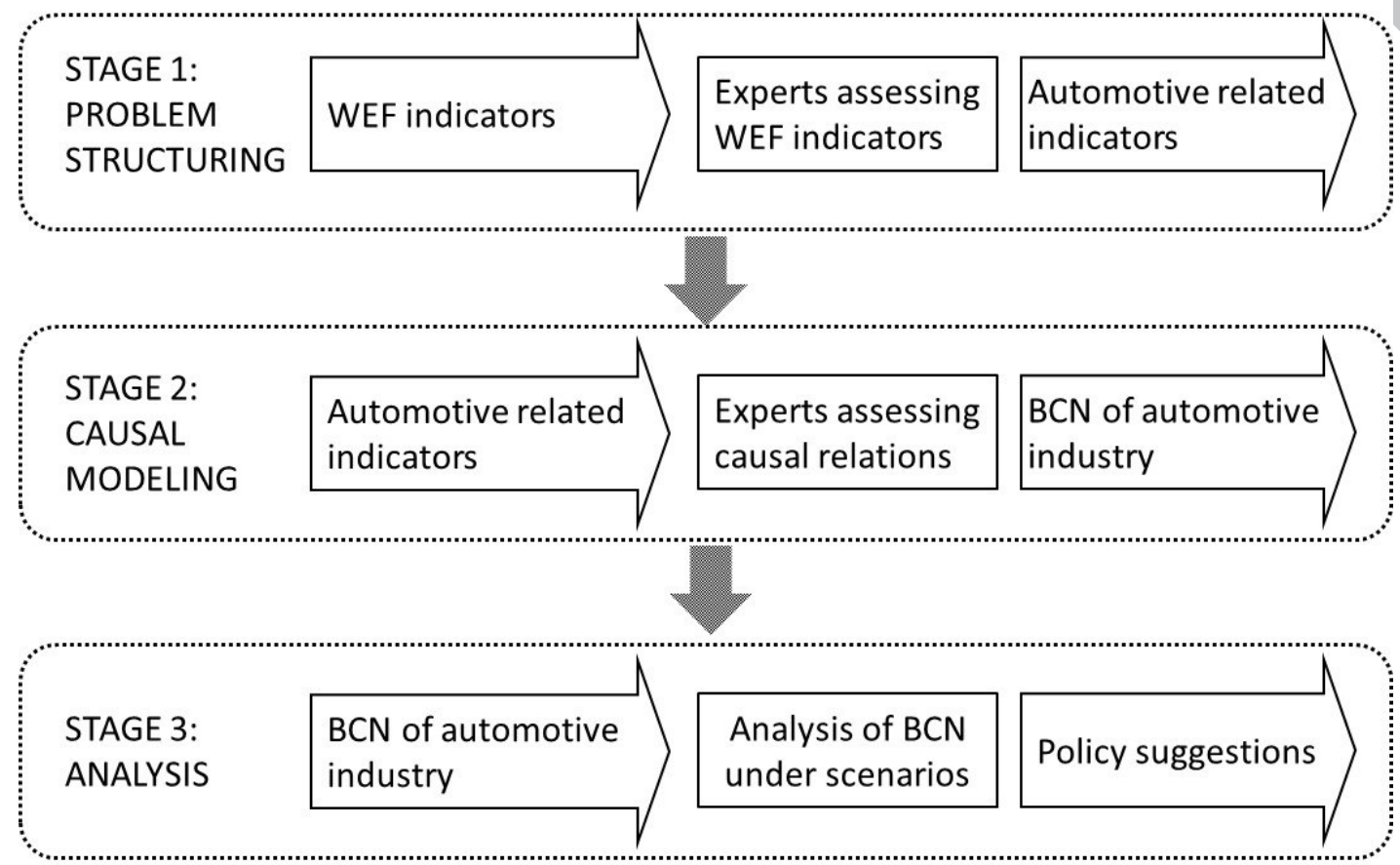

Figure 1. Framework of the proposed methodology

In the problem structuring stage, the WEF indicators are the inputs and a list of automotive industry related indicators are the outputs. We create this list as a result of an online survey of members of the automotive industry stakeholder groups (see subsection 3.1).

The causal modelling stage takes the output from Stage 1 as the input and generates the BCN of the automotive industry as the output. Initially, relationships among the indicators are determined through a workshop where the participants are members of the automotive industry stakeholder groups. In this workshop, experts assess the causal relations between the automotive industry competitiveness indicators. Subsequently, we develop a BCN by integrating the results of the workshop with WEF data (see Subsection 3.2).

In the final stage, we use the $\mathrm{BCN}$ to analyse the competitiveness of the Turkish automotive industry based on automotive industry-related indicator data under different scenarios. The outputs of Stage 3 are the policy suggestions which we develop in order to shape the future of automotive industry competitiveness (see Subsection 3.3). 
This methodology resembles the methodology used by Kao et al. (2008) for assessing national competitiveness in the sense that it combines hard and soft data, i.e., WEF indicators and expert opinions. The following subsections present the details of the proposed methodology.

\subsection{Problem structuring}

Problem structuring methods (PSM) are comprised of interactive and participatory modelling approaches where the aim is to assist groups with diverse composition to alleviate a complex, problematic situation of common interest (Mingers \& White, 2010). The problem structuring stage relevant to the automotive industry is highly sophisticated in terms of the technical complexity, the degree of uncertainty, and the divergence of values and interests. There are many factors that may be included in the system, and the relationships among them are also very difficult to formulate using classical hard systems approaches. The industry is related to various stakeholders including the government, other industries, such as the steel and tire industries, the suppliers, universities, exporters and importers and customers. To address such a complex system, we apply a type of soft systems approach. In fact, soft systems approaches were designed to address complex problem situations, such as the competitiveness of the automotive industry, that are messy, unstructured, ill-defined and affected by human factors (Daellenbach and McNickle, 2005). We collected information from various stakeholders to structure the competitiveness problem in the automotive industry. We started with an effort to understand the complexity associated with the competitiveness of this industry (Ackermann, 2012).

In the first stage, the aim is to identify the components (i.e., the automotive related indicators) of the competitiveness problem of the automotive industry. For this purpose, we did a survey with members of the automotive industry stakeholder groups. Because this study analyses the competitiveness of the automotive industry in association with the national competitiveness perspective, we use country level indicators in the WEF Global Competitiveness Report 2012-2013 (WEF, 2012). The WEF (2012) investigates 144 economies based on 111 indicators and classifies the indicators into twelve basic pillars. In the first stage of this study, we identify the automotive competitiveness indicators from the following twelve pillars:

- Institutions (19 indicators)

- Infrastructure (8 indicators) 
- Macroeconomic Environment (5 indicators)

- Health and Primary Education (11 indicators)

- Higher Education and Training (8 indicators)

- Goods Market Efficiency (15 indicators)

- Labour Market Efficiency (9 indicators)

- Financial Market Development (9 indicators)

- Technological Readiness (9 indicators)

- Market Size (2 indicators)

- Business Sophistication (9 indicators)

- Innovation (7 indicators)

Due to the large number of indicators to be assessed, it was not possible to suggest pairwise comparisons. Therefore, we conducted an online direct-rating survey to evaluate the importance of each WEF indicator for the automotive industry competitiveness. For this purpose, we used a 1 to 10 scale where the participants are asked to rate the more important indicators using higher scores. We used direct ratings because they are more reliable and more accurate than point allocations where 100 points are distributed among the objects (Bottomley \& Doyle, 2013). We received 72 responses from a wide spectrum of participants including members of the Turkish Automotive Manufacturers Association (Otomotiv Sanayii Derneği OSD), suppliers, distributors and authorised dealers involved in the supply chain, a select group of related bureaucrats, press/media members, finance and private research institutions, and academics.

Subsequently, we ranked all indicators in descending order, and chose those with a score of 8.5 or higher to feature in the structure of the problem. We determined this cut-off point (i.e., 8.5) based on the consensus of the top executives from Turkish Federation of Industrial Associations (Sektörel Dernekler Federasyonu - SEDEFED) and the OSD as well as the analysis of the results, which indicated a larger gap between the indicators with scores below 8.5.

According to the results of the survey, the following 15 indicators impact the future competitiveness of the automotive industry (in alphabetical order):

- Availability of latest technologies

- Availability of scientists and engineers

- Company spending on Research and Development (R\&D) 
- Degree of customer orientation

- Domestic market size index

- Ease of access to loans

- Extent and effect of taxation

- Firm-level technology absorption

- Foreign market size index

- Local supplier quality

- Production process sophistication

- Quality of innovation

- Quality of scientific research institutions

- Total tax rate

- University-industry collaboration in R\&D

We then discussed the results of this survey with the executives from SEDEFED, OSD, and TÜSİAD Sabanci University Competitiveness Forum (Rekabet Forumu - REF) as well as the main stakeholders of the automotive industry. To be able to create the link between national competitiveness and industrial competitiveness and to see the effect of the macro variables on industrial competitiveness, we included three additional indicators specific to the automotive industry to the indicators affecting automotive competitiveness. These additional indicators are;

- Automotive foreign market effectiveness (Export competitiveness index)

- Automotive production process sophistication (Revealed comparative advantage)

- Domestic automotive market size (number of vehicles per 1000 people)

Automotive foreign market effectiveness is the revealed competitiveness index for the automotive industry. Data are provided by the REF, which equals the logarithmic difference between the export and the import advantage indices. Positive and negative values reflect comparative advantages, and disadvantages, respectively.

Automotive production process sophistication (reveals the comparative advantage of the country due to its automotive industry activity) is a composite index where the industry's share in exports (total exports of the industry divided by total exports of the country) in the country is divided by the industry's share of the global exports (total exports of the industry in the world divided by total exports of all industries in the world). 
The size of the domestic market is the natural logarithm of the sum of the gross domestic product valued at purchasing power parity (PPP) plus the total value (PPP estimates) of imports of goods and services, minus the total value (PPP estimates) of the exports of goods and services. The PPP estimates of imports and exports are the product of exports as a percentage of GDP and GDP valued at PPP.

As a result, we identified 18 indicators as having an impact on the competitiveness of the automotive industry in the problem structuring stage.

\subsection{Causal modelling}

It was crucial to reveal the connections among the indicators in order to conceptualise the relationships among them. For this purpose, we used a Delphi-type (Şahin 2001; Rowe and Wright, 2011) group decision making approach, which is a process oriented approach similar to other soft systems approaches (Keys, 2007). Expert judgments are found to be very useful in the literature to structure the problems, to indicate key variables and to examine the relationships among the variables (Morgan, 2005). For example, Fauss et al. (2009) emphasise that multiple experts from various disciplines and institutions, including government, industry, non-profit and academia, can provide a better understanding of the possible exposure routes for a specific product than any single expert.

Therefore, we organised a workshop with 29 participants to obtain the stakeholder perceptions relevant to the problem structure. A broad spectrum of participants including academics and key people from the automotive industry, members of non-governmental organisations, consultants, representatives from subsidiary industries, members of the public, and journalists attended the workshop to provide different perspectives on the subject. The workshop lasted one day and included four phases. In the first phase, we gave an informative presentation of the study, the process, and the indicators to the participants. In the second phase; we grouped the participants randomly to ensure homogeneity, and asked each group to make pair-wise comparisons to determine the links between the indicators. We instructed the participants to evaluate these relations on a scale from -3 to +3 (see Table 2 for the definitions of the scale). 
Table 2. Linguistic expressions used in the workshop

\begin{tabular}{ll} 
Scale levels & Linguistic expression \\
\hline+3 & Strong positive relation \\
+2 & Moderate positive relation \\
+1 & Weak positive relation \\
0 & No relation \\
-1 & Weak negative relation \\
-2 & Moderate negative relation \\
-3 & Strong negative relation \\
\hline
\end{tabular}

After the second phase; we summarised the results of the group opinions in terms of the first quadrant, second quadrant, median, and magnitude for each indicator. The first quadrant is the numerical value separating the lower quartile of the data sample, and the third quadrant is the numerical value separating the upper quartile of the data sample. The magnitude is the difference between the third and the first quadrant values. When the magnitude is low, there is a consensus on the given values of the decision makers.

In the third phase, we gave the participants the previous survey again, but they received the results of all groups as extra information. We asked the participants to compare their answers to the group statistics and to review their decisions. This stage enabled the groups to consider different perspectives and to reach a compromise decision concerning the relationships.

In the fourth and final stage of the workshop, we asked the participants to make a final review of all the comparisons. We provided detailed explanations for those indicators where there was significant disagreement to enable negotiations and reach a final consensus. As a result; we obtained the final revised scores of the relationships after the participants voted for the second time. We then used these scores to establish the BCN which we analyse using the indicator data in the next stage.

\subsection{Analysis of the relationships using BCNs}

In the third stage, we operationalised the BCN obtained as an outcome of the second stage by using the data for the 18 indicators. In the following subsections, we present the fundamentals of BCNs and explain the BCN of the Turkish automotive industry.

\subsubsection{Fundamentals of BCNs}

$\mathrm{A} \mathrm{BCN}$ is a directed causal network that is decision-focused, data-driven and transparent (Williams and Cole, 2013). It is especially useful in modelling uncertainty in a domain and it has been applied to cases that require the diagnosis of problems from a variety of input data 
(Nadkarni and Shenoy, 2004). A BCN is a graphical representation of the probabilistic relationships between multiple variables where the nodes represent the variables and the arcs stand for the relationships among the variables (Wu et al., 2012a). The BCN has the advantage of having no rigid statistical assumptions. It graphically displays a directed acyclic graph and represents a set of conditional independence constraints among a given number of variables and their related conditional probability distributions ( $\mathrm{Wu}, 2010)$. These BCNs can handle incomplete data sets and help easily model causal relationships to gain understanding about a problem domain and make predictions in the presence of interventions. They facilitate the analysis of potential actions that can be followed by policy makers (Anderson and Vastag, 2004). Additionally, in conjunction with Bayesian statistical techniques, they facilitate the combination of domain knowledge and data.

A BCN is a directed acyclic graph (Cinicioglu et al, 2012) where, if there is a directed arc from a variable $X_{1}$ to a variable $X_{2}$, then we call $X_{1}$ the parent of $X_{2}$ and $X_{2}$ the child of $X_{1}$. As given in Equation 1, each variable in a $\mathrm{BCN} X_{1}, \ldots, X_{N}$ possesses a probability distribution given its parents, and the product of these conditional probability distributions constitutes the joint probability distribution of the network.

$$
P\left(X_{1}, \ldots, X_{N}\right)=\prod_{i=1}^{N} P\left(X_{i} \mid P a\left(X_{i}\right)\right)
$$

where $\mathrm{Pa}\left(X_{i}\right)$ denotes the set of parents of $X_{i}$. It is also possible to represent a BCN as a table so that the table entries are the conditional probabilities of the variable based on their parents. The fundamental assumption of a $\mathrm{BCN}$ is that when the conditionals for each variable are multiplied, the joint probability distribution for all variables in the network is obtained (Mishra et al., 2001). In a simple Bayes net where A effects B and B effects C; it is assumed that $\mathrm{P}(\mathrm{A}, \mathrm{B}, \mathrm{C})=\mathrm{P}(\mathrm{A}) \otimes \mathrm{P}(\mathrm{B} \mid \mathrm{A}) \otimes \mathrm{P}(\mathrm{C} \mid \mathrm{B})$ where $\otimes$ denotes point wise multiplication of tables. In fact, the rule of total probability tells us that $\mathrm{P}(\mathrm{A}, \mathrm{B}, \mathrm{C})=\mathrm{P}(\mathrm{A}) \otimes \mathrm{P}(\mathrm{B} \mid \mathrm{A}) \otimes \mathrm{P}(\mathrm{C} \mid$ $\mathrm{A}, \mathrm{B})$. These two expressions depend on the assumption that $\mathrm{P}(\mathrm{C} \mid \mathrm{A}, \mathrm{B})=\mathrm{P}(\mathrm{C} \mid \mathrm{B})$, i.e., $\mathrm{C}$ is conditionally independent of A given B. In BCNs, absence of an arc from a variable to another means that the two variables are conditionally independent.

There are a number of steps in building a BCN (Korb \& Nicholson, 2011). First, the variables of interest must be identified. This involves identifying the nodes to represent as well as their possible values. Second, the structure of the network must be determined. This step includes capturing of the qualitative causal relationships among the variables. After specifying the structure of the network, the next step is to quantify the relationships between the connected nodes using probability distributions of the variables. For that purpose, two 
different approaches have been used to construct BCNs: automatically learning the structure of the network and the numerical parameters from data, known as a "data-based approach", and manual building of the network based solely on human expert knowledge, known as a “knowledge-based approach" (Onisko, 2008; Nadkarni \& Shenoy, 2004).

The data-based approaches use conditional independence theory to construct models from data. Recently, data mining techniques have been proposed as a way to develop BCNs. Several search algorithms such as simulated annealing algorithms, genetic algorithms, and Three Augmented Naïve Bayes (TAN) algorithms (Cerquides and Mantaras, 2005) have been developed for this purpose (Wu, 2010; Hruschka and Ebecken, 2007; Baesens et al., 2004; Wu et al. 2012). The knowledge-based approach, on the other hand, uses the causal knowledge of domain experts to construct networks.

Hybrid approaches, such as the approach used in this study, can also be used to construct BCNs. The structure is built on expert knowledge, and the numerical parameters for all nodes are learned from the numerical data. Nadkarni and Shenoy (2004) define such networks, namely BCNs, as the most effective networks because they combine the qualitative structure based on expert knowledge with the quantitative probabilities identified and revised using hard data. BCNs not only provide clear graphical structures with natural causal interpretations that most people find intuitive to understand; but they also provide good estimates even when some predictors are missing (Nicholson et al, 2008).

Due to the complexity of the global competitiveness analysis of a country and its impact on the competitiveness of the automotive industry in particular, we decided to use the BCNs in this study. The variables of the system and the cause-effect relations among them were elicited based on the expert knowledge. In fact, BCNs are good tools for expert elicitation and breaking down the competitiveness analysis into lower dimensions (Wu et al., 2012b). On the other hand, as Williams and Cole (2013) noted, the use of experts to specify the variables to be included in the model as well as the relations among the variables make the model "credible for", "accessible to" and "owned by" the experts of the automotive sector. Although in some situations it is unusual to have a human expert nearby when performing data mining and structuring the $\mathrm{BCN}$, this was not the case in this study where it was possible to reach 72 experts in the first stage, 29 experts in the second stage and 6 experts in the third stage. The final reason for using expert elicitation is that there generally is no reliable feedback on the accuracy of causal models based on data mining techniques (e.g., Wu et al., 2012b). However, in this study, the findings of the developed BCN are validated iteratively with feedback from the experts in each stage. 


\subsubsection{BCN Model of the Automotive Industry}

To be able to use the $\mathrm{BCN}$ for analysing automotive industry competitiveness and developing policy suggestions, we initially questioned the conditional dependence and independence assumptions because in BCNs, variables connected by arrows must be conditionally dependent and variables lacking a direct connection must be conditionally independent. In addition, we examined, discussed and verified the direct and the indirect relations with the domain experts because conditional independencies are critical in making inferences using BCNs. We eliminated the circular relationships where they were present, in favour of the stronger relationship.

As a second step, to quantify the relationships between connected nodes, the $\mathrm{BCN}$ model learned the parameters for the related network structure from the data. We initially transformed the data into a form where we classified the ratings of each variable into three states: low, medium and high. In the BCN literature, this process is referred to as discretisation (Häger, \& Andersen, 2010). Because WEF measures the values of most of the variables on a seven-point scale, we discretised the variables simply by dividing the scale into three states of $[1,3)$ as low, $[3,5)$ as medium and [5,7] as high. For those variables (Automotive production process sophistication, Automotive foreign market efficiency, Automotive domestic market size index, Total tax rate) with values different from the 1-7 scale, we divided the related range into three intervals that corresponded to the three states by checking the break points in data as is explained in Aktas et al. (2007).

Although BCNs offer a very efficient method for building models of domains with inherent uncertainty, evidence transmission is a tedious job even for a very simple BCN (Jensen \& Nielsen, 2007). Fortunately, there are several commercial software tools such as Netica (www.norsys.com), which is used in this study. We decided to use Netica because it is capable of compiling Bayes nets into junction trees of cliques for fast probabilistic reasoning. This software can learn probabilistic relations from data (including expectation maximisation and gradient descent learning) and determine the parameters associated with the nodes even for incomplete data sets. Moreover, the user interface is simple, and Netica allows the analysts to involve the owners of the problem in the scenario analysis process by immediately updating the probabilities of the states of the variables of interest.

The resulting automotive competitiveness model had 18 decision variables, 36 relationships between variables, and 1,206 conditional probabilities (see Figure 2). All variables have different probabilities based on the existing causal relationships between the variables. For example, there is a $15.9 \%$ probability that the innovation capacity of the analysed 
countries is low, whereas the probability of having a "medium" performance level in the innovation capacity level is $62.5 \%$. Moreover, the average level of all of the countries analysed for innovation capacity is 4.11 , which is given at the bottom of the variable named "Innovation capacity".

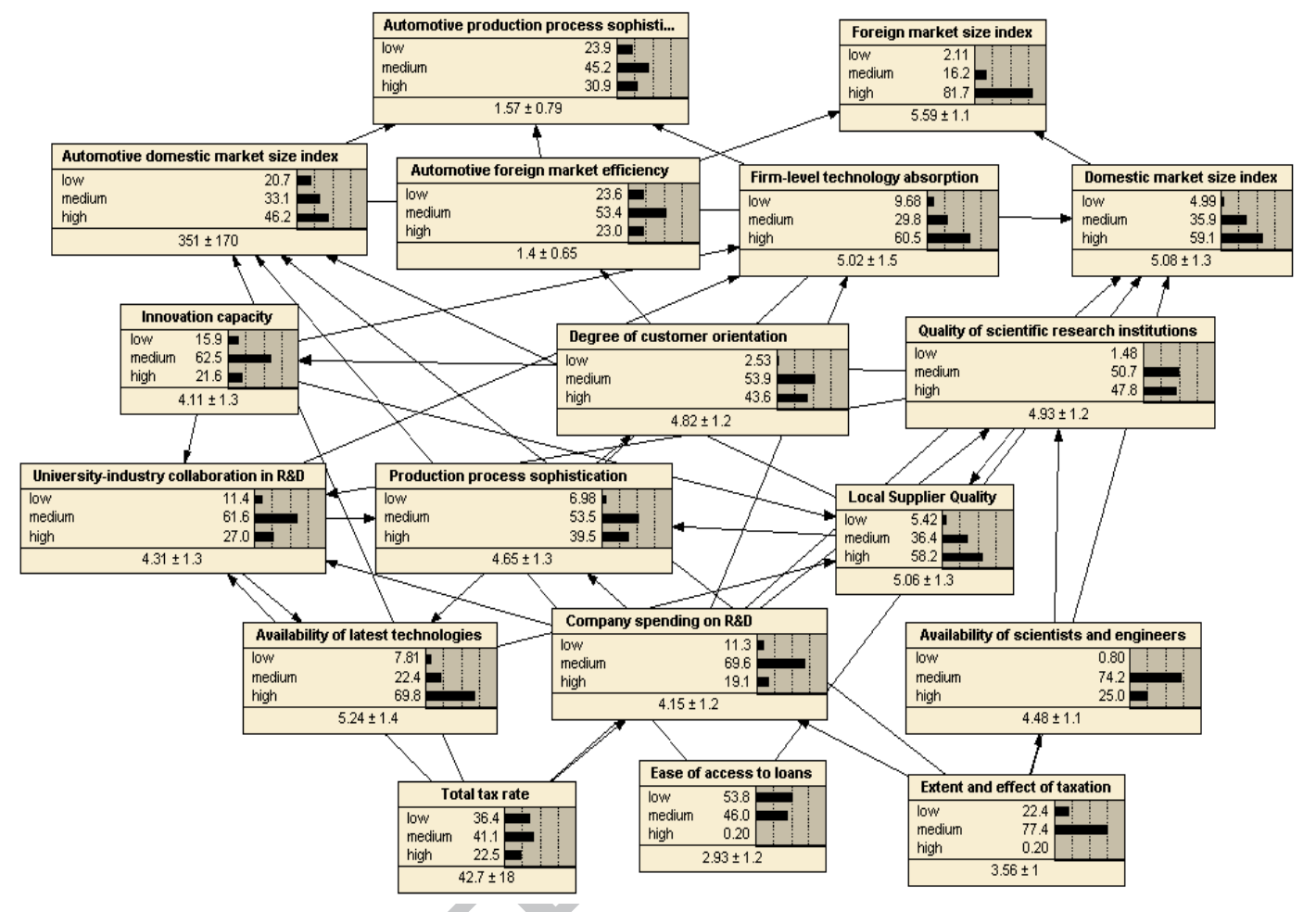

Figure 2. BCN for Automotive Industry

As explained above, we built the structure of the developed BCN based on expert knowledge, and the model learned the numerical parameters from the data.

The countries to be included in the data set as benchmarking countries for Turkey were selected by the executives from the SEDEFED, the OSD, and the REF according to the following criteria:

- Automobile manufacturers that produce goods for both domestic and global markets:

Austria, Belgium, Canada, Czech Republic, Bulgaria, Hungary, Indonesia, Mexico,

Netherlands, Poland, Portugal, Romania, Slovak Republic, Slovenia, Spain, Sweden,

Turkey, United Kingdom.

- BRIC Countries: Brazil, Russia, India, China.

- Brand holders: France, Germany, Italy, Korea Republic, United States.

In fact, the selected countries also constitute the top 20 car manufacturers (OICA, 2010) as well as the European benchmark countries. 
We checked the resulting net for validity with the expert group at the end of the analysis. The states of several variables were changed, and the validity of the response of the system to those changes was verified based on comparisons of policy suggestions given in the CARS 21 report (EC, 2010) as well as in the Automotive Industry Special Working Group Report that is cited in Turkey's $9^{\text {th }}$ development plan (SPO, 2006) and in The Republic of Turkey's Ministry of Development's Medium Term Plan (TRMD, 2012)

\section{Developing Policy Suggestions}

Once a BCN is constructed, it can be used to make inferences about the variables in the model (Nadkarni and Shenoy, 2004). Inference (also called probabilistic inference) in a BCN is based on the concept of evidence propagation (Mishra et al., 2001). Evidence propagation refers to an efficient computation of the marginal probabilities of the variables of interest conditional on the arbitrary configurations of other variables, which constitute the observed evidence.

The process of propagation is performed via a flow of information through the network (Korb and Nicholson, 2011). This information flow is not limited to the directions of the links. BCNs can be conditioned upon any subset of their variables because they provide full representation of probability distributions. The propagation process in BCNs can be performed in two ways: diagnostic and predictive. In diagnostic propagation, the reasoning is conducted from the symptoms to the cause, while in predictive propagation, reasoning follows from new information about causes towards new beliefs about effects in the directions of the network links.

Because the aim of this study was to analyse the competitiveness of the automotive industry and to develop policy suggestions, we analysed all three indicators related to the automotive sector's performance in the form of diagnostic propagation: Automotive domestic market size, Automotive foreign market effectiveness, and Automotive production process sophistication. During a diagnostic propagation, we used the "sensitivity analysis" feature of Netica to identify which nodes were the most informative in crystallising the states of the analysed node.

We first investigated the Automotive domestic market size indicator. The sensitivity analysis of this indicator showed that the most significant factor is Local supplier quality. A high level of local supplier quality must be maintained if the automotive domestic market size is to improve. Similarly, when Local supplier quality was in question and the sensitivity of this indicator was analysed, the Innovation capacity was found to be the key indicator. For a 
leap from the medium to the high level in local supplier quality, a serious improvement must be made in the country's innovation capacity. It became clear that the most influential indicator for the Innovation capacity was the Quality of scientific institutions and the key indicator for the Quality of scientific institutions was Company spending on $R \& D$. As the result of an increase in corporate spending on $R \& D$, the domestic automotive market size will grow naturally. Although there may not be a direct relationship between the Company spending on $R \& D$ and the Automotive domestic market size, as can also be seen in Figure 3 , an increase in the Company spending on $R \& D$ also leads to considerable growth in the Automotive domestic market size.
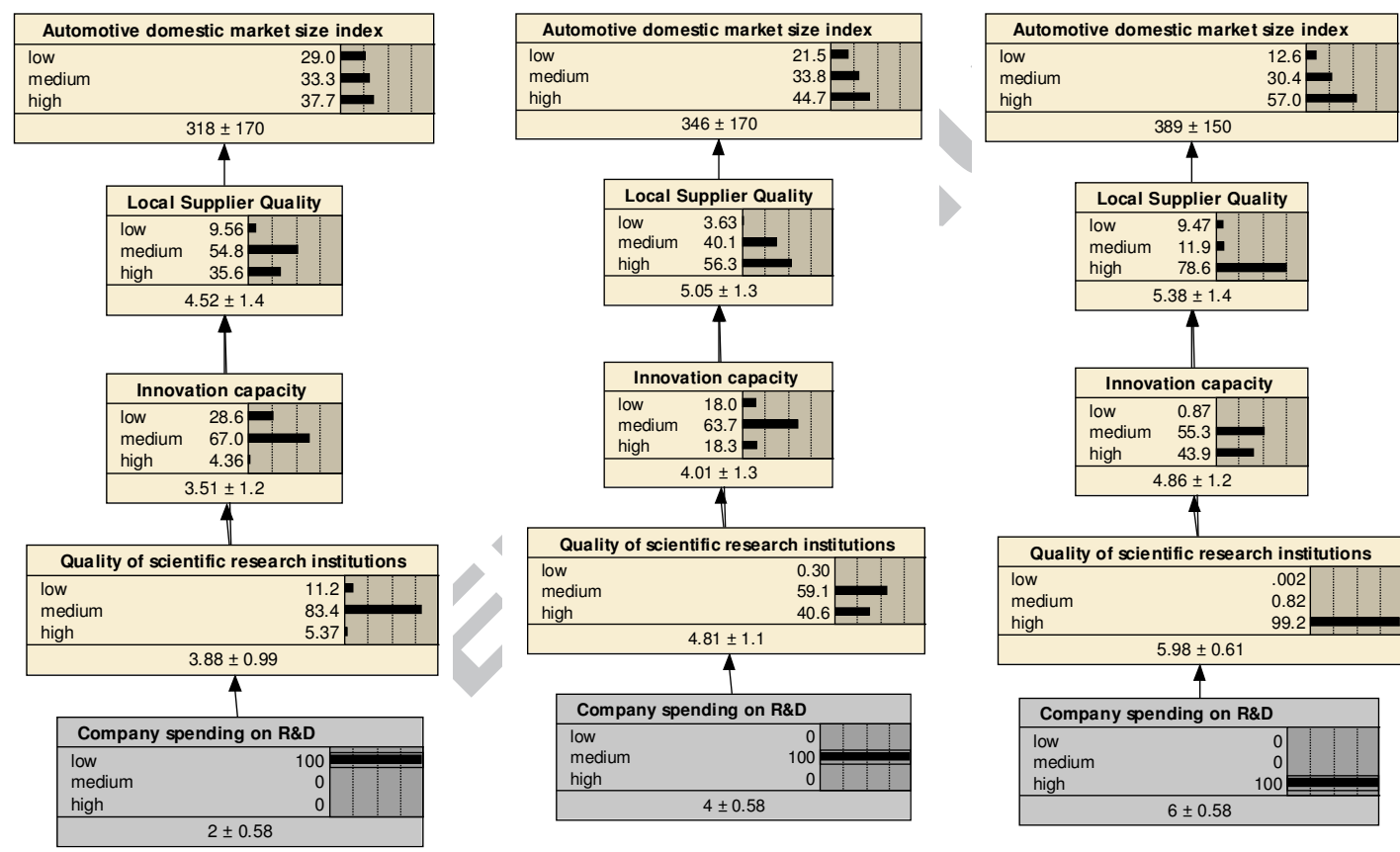

Figure 3. The relationship between the Company Spending on $R \& D$ and the Automotive Domestic Market Size 
Table 3 Changes that will have a positive impact on Turkey's Automotive Domestic Market Size

\begin{tabular}{lll}
$\begin{array}{l}\text { Indicators that have a short-term impact } \\
\text { on the Automotive domestic market size }\end{array}$ & $\begin{array}{l}\text { Turkey's rating } \\
\text { in the WEF } \\
\text { Report }\end{array}$ & \\
\hline Local supplier quality & 4.6 & Medium \\
Innovation capacity & 3.1 & Medium (Lower threshold) \\
Company spending on R\&D & 3 & Low \\
Extent and effect of taxation & 2.9 & Low \\
Availability of latest technologies & 5.5 & High \\
Ease of access to loans & 2.6 & Low \\
University-industry collaboration in R\&D & 3.4 & Medium \\
\hline
\end{tabular}

Table 3 summarises the results of the sensitivity analysis conducted on the Automotive domestic market size and provides the indicators that have a positive impact on the Automotive industry domestic market size.

The sensitivity analysis conducted on the two indicators used to measure the competitiveness level of the automotive sector - namely, the Automotive foreign market effectiveness and the Automotive production process sophistication - resulted in the same variables listed in Table 3. Therefore, these variables were further investigated through a scenario analysis approach to develop policy suggestions about the sector.

Initially, we developed both optimistic and pessimistic scenarios related to Turkey's automotive industry (Table 4). In the optimistic scenario, we assumed that the values of the seven variables that influence the performance of the automotive industry would improve and increase to one level above their current level (e.g., the Local supplier quality improved from Medium to High). On the other hand, in the pessimistic scenario, we assumed that each of the seven indicators would fall one level lower (e.g., the Local supplier quality decreased from Medium to Low). We analysed the resulting system performance for these scenarios. We conducted a predictive propagation to observe the effects of different states in the network structure. Table 5 and Figure 4 present the prior and posterior marginal probabilities for the optimistic and pessimistic scenarios. 
Table 4 Levels of the seven indicators in the scenarios

\begin{tabular}{lll} 
Indicators & $\begin{array}{l}\text { Level in an Optimistic } \\
\text { Scenario }\end{array}$ & $\begin{array}{l}\text { Level in a } \\
\text { Pessimistic Scenario }\end{array}$ \\
\hline Local supplier quality & High & Low \\
Innovation capacity & High & Low \\
Company spending on R\&D & Medium & Low \\
Extent and effect of taxation & Medium & Low \\
Availability of latest technologies & High & Medium \\
Ease of access to loans & Medium & Low \\
University-industry collaboration & High & Low \\
in R\&D & & \\
\hline
\end{tabular}

Table 5 Prior and posterior marginal probabilities for two scenarios

\begin{tabular}{|c|c|c|c|}
\hline Variables & $\begin{array}{l}\text { Prior } \\
\text { marginals }\end{array}$ & $\begin{array}{l}\text { Posterior marginals / } \\
\text { Optimistic Scenario }\end{array}$ & $\begin{array}{l}\text { Posterior marginals / } \\
\text { Pessimistic Scenario }\end{array}$ \\
\hline \multirow{3}{*}{$\begin{array}{l}\text { Domestic automotive } \\
\text { market size }\end{array}$} & 20.7 (low) & 1.05 (low) & 19 (low) \\
\hline & 33.1(medium) & 23.2(medium) & 51 (medium) \\
\hline & 46.2 (high) & 75.7 (high) & 30 (high) \\
\hline \multirow{3}{*}{$\begin{array}{l}\text { Automotive foreign } \\
\text { market effectiveness }\end{array}$} & 23.6 (low) & $8.49($ low $)$ & 24.5 (low) \\
\hline & 53.4(medium) & 77 (medium) & 51.8(medium) \\
\hline & 23(high) & 14.5(high) & 23.7(high) \\
\hline \multirow{3}{*}{$\begin{array}{l}\text { Automotive production } \\
\text { process sophistication }\end{array}$} & $23.9($ low $)$ & 10.4(low) & $21.8($ low $)$ \\
\hline & 45.2(medium) & 54.3(medium) & 54.5(medium) \\
\hline & 30.9(high) & 35.4(high) & 23.7(high) \\
\hline
\end{tabular}

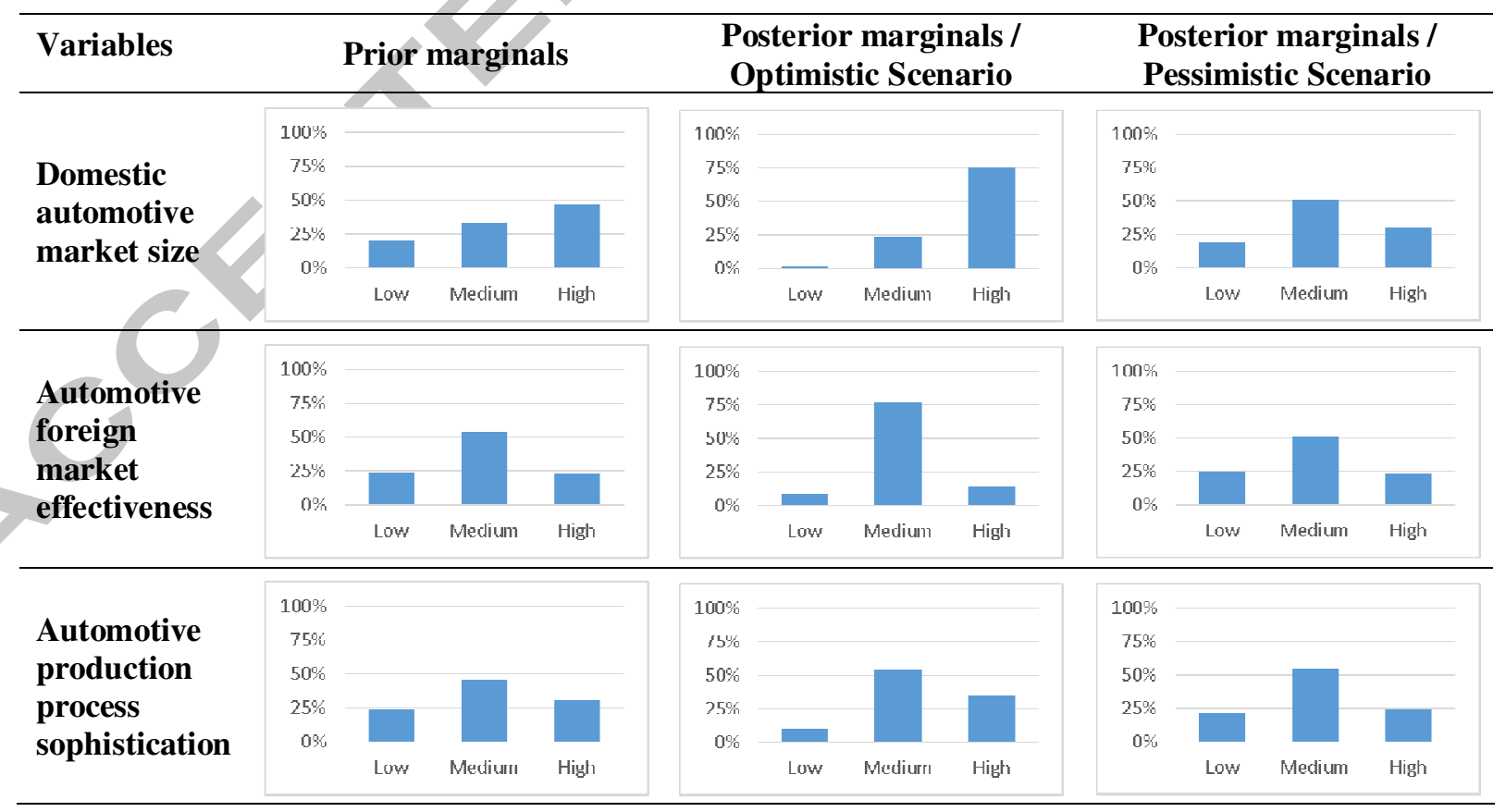

Figure 4. Prior and posterior marginal probabilities under two different scenarios 
According to the results given in Table 5 and Figure 4, if Turkey improves by increasing the values of all seven variables to the next upper level (i.e., the optimistic scenario), the probability that the Domestic automotive market size will be high is $75.7 \%$, the probability that the Automotive foreign market effectiveness will become medium is $77 \%$, and the probability that the Automotive production process sophistication will be medium is $54.3 \%$. However, if the situation worsens and the values of those variables drop one level (i.e., the pessimistic scenario), then the Domestic automotive market size will decline to the medium level with $51 \%$ probability. Although it seems that there is no critical difference in the levels of the Automotive foreign market effectiveness and the Automotive production process sophistication indicators, the probability that they are at a low level increases, while the probability that they are at a high level decreases.

As this analysis shows, to improve the competitiveness of its automotive industry, Turkey should focus primarily on: the local supplier quality, innovation capacity, company spending on R\&D, the extent and the effect of taxation, the availability of the latest technologies, the ease of access to loans, and university-industry R\&D collaborations. These results align perfectly with the policies suggested by the EC (2010), the TRMD (2012) and the SPO (2006).

A significant part of the added value produced by vehicles in the automotive industry has been shifting from brand owners to suppliers and businesses that assemble vehicles. In the future, more than $75 \%$ of the value of vehicles will be created by automobile supply chains. Hence, the design and development phases of a vehicle as a whole will be carried out as a common effort shared by supplier operations in different countries. Therefore, the accommodation of suppliers with technological competence needs to be managed along with productivity and cost cutting. It is very important to not only make vehicles safe but also to possess appropriate vehicles and efficient manufacturing and management processes for testing, analysis, design verification and licensing that make the manufacture of vehicles feasible and profitable. Hence, the integration and the need for close partnerships between suppliers and Original Equipment Manufacturers are also vital (Ulengin et al., 2010).

The global competitiveness of the automotive industry is related directly to a stable and advanced domestic market. Both the manufacturing processes and the general taxation system implemented in the sale and the use of products, therefore, bear great significance. On the other hand, investment and R\&D incentives that endow the industry with global competitiveness and ensure its maintenance are closely linked to tax regulations. This is 
consistent with the results of Guan et al. (2006) where the authors determined a close internal relationship between technological innovation capability and competitiveness for enterprises. Generally, incentives are aimed at enhancing the productivity of the industry through certain cuts in taxes incurred during the manufacturing process.

Currently, there are structural problems with taxes levied in the domestic market, and these problems constitute an important obstacle to the growth of the local market. In addition, high taxes particularly on automobiles limit the growth of the domestic market and the consolidation of the industry's output. Successful strategic planning should consider this widespread impact of the tax system.

One of the most dramatic negative effects of the global economic crunch is the drop in customer confidence. The global crisis has hit the Turkish economy in three areas: foreign trade, finance and expectations. The model used in this study emphasises that difficulties in gaining access to loans could lead to huge losses in the automotive market. Because automobiles are one of the most important consumer goods in terms of total household expenses, motor vehicle demand is highly vulnerable to cycles in trade. For this reason, the current situation presents a bottleneck for the sale of new vehicles.

The Republic of Turkey's Ministry of Development published its Medium Term Plan (TRMD, 2012) in October 2012 emphasising the need to reinforce confidence and stability in the finance sector, which is one of the most influential factors in the competitiveness of the Turkish automotive industry. This is in full accordance with the findings of our research. Regulation, audit and improvement of the finance sector in compliance with international standards and the new work carried out after the crisis under the leadership of the G-20 platform will have a great effect on improving the competitive strength of the Turkish automotive industry.

Similarly, the TRMD (2012) places great emphasis on scientific and technological competence, converting this competence into economic and social benefits, and improving the innovative capabilities of the private sector that plays a pivotal part in converting R\&D efforts into products and increasing their contribution to competitiveness. The findings of the model put forth in this study, which we carried out to determine the variables that affect the automotive industry's competitiveness, shows that R\&D plays a key role in enhancing the competitive power of the automotive industry.

In this context, as suggested by the TRMD (2012) and the results of this research, it is of primary urgency to improve collaborations between institutions and organisations within the scope of national innovation. In the meantime, it is crucial to take into account their 
missions and activities to enhance the effectiveness of the private sector in the system and to increase the R\&D capacity and the demand of the private sector, starting with small and medium Enterprises (SMEs). In addition, programmes must be developed to improve collaboration between the private sector, universities and research institutions. R\&D collaboration must be supported, and the quantity and the quality of researchers must be improved in parallel with the needs of the private sector. In public research institutions and higher education institutions, it is necessary to continue establishing competence/specialist centres and central research laboratories and carrying out advanced research. The private sector enterprises must also be supported through incentives such as tax exemptions. This and similar strategies based on state policy will play a huge role in improving the competitive strength of the Turkish automotive industry.

The automotive industry is extremely significant and strategic for many reasons: high added value, high employment, competitive nature, utilisation of many technologies and a multiplier effect on the technological development of the country. Therefore, special attention must be paid to the automotive industry, and this attention must be used as an effective tool to increase $\mathrm{R} \& \mathrm{D}$ activities.

\section{Conclusions and Future Directions}

The world has entered a very significant period of change. The importance of economic, political, technological, socio-cultural, ecological and demographic changes has been growing, and the success of any industry in any country is no longer possible solely through the means of that industry. Industrial competitiveness has become more closely associated with the country's global competitiveness.

Several studies assess the competitiveness of the automotive industry based on a large spectrum of global competitiveness attributes. Previous studies have analysed the impact of only one factor, such as knowledge transfer or technology, on the automobile industry's competitiveness. However, the competitiveness level of the industry is also highly dependent on the global competitiveness level of the nation in which it operates. To the best of our knowledge; this paper presents the first study that uniquely analyses how improvements in different indicators of national competitiveness influence the success of a specific industry. Analysis conducted in this study uses the WEF's competitiveness indicators that have been identified to affect the competitiveness of the automotive industry.

In fact, because relationships among the indicators and their relative influence on the competitiveness of an industry differ from one industry to another, they should be specified 
individually for each industry. This study aimed to analyse these relationships for the automotive industry in particular. We developed a three-stage methodology based on BCNs to analyse the competitiveness of the automobile industry with a detailed set of indicators and we expect to provide an important contribution toward developing a useful road map for policy makers.

The problem structuring stage of the proposed methodology enables us to take into account different stakeholders with various world views, possibly with conflicting perceptions about the major issues and factors influencing the competitiveness of the automobile industry. Therefore, this first stage provides a structured approach to the issues surrounding the competitiveness of the automotive industry. It facilitates dialogue between various stakeholders with the aim of achieving a greater shared perception of the problem situation. It addresses the "what" questions through questionnaire surveys and workshops. Next, the "how" questions are addressed in the later stages of the methodology through the BCNs. Simulations and scenario analyses based on the BCN makes it possible to resolve the problem according to the stakeholders rather than the analyst. As a result, the proposed methodology successfully addresses the complex problem situation of the automotive industry and highlights some important policies to improve its competitiveness.

The use of BCNs in the methodology makes it possible to decode the relationships among the variables of interest and model the causal relationships and thus to gain understanding about the basic dimensions that are relevant to the automotive industry competitiveness. This approach is especially useful in modelling uncertainty in this framework and helps to predict the consequences of policy interventions.

Specifically, the BCN allowed an in-depth analysis of the causal relationships among the variables and made it possible to test different scenarios incorporating policy interventions and the uncertainty of the future. The evidence for the successful use of the BCN in such a domain is relevant to and important for the discipline of OR.

A final note is given regarding the comparison of the BCNs to Artificial Neural Networks (ANN). The structure of a BCN is more transparent than black box methods, such as ANNs, and this transparency allows efficient and interactive communication between policy analysts and policy makers. This combination of objective data and subjective expert judgments enables BCNs to produce consistent models of systems under investigation.

In summary, BCNs are powerful and practical artificial intelligence tools because they use expert knowledge, acquire knowledge from data, assess uncertainty and work well in making projections into the future (Naim, 2008). To take advantage of these features, we used 
BCNs to analyse the competitiveness of the automotive industry and informing policy interventions through scenario analyses.

We applied the proposed methodology in in Turkish automotive industry owing to the support of the SEDEFED and the OSD. We developed scenario analyses to suggest policies for improving the competitiveness of the automotive industry in Turkey.

The methodology shows that the future competitiveness of the Turkish automotive industry depends to a large extent on the local supplier quality, the extent and the effect of taxation, the ease of access to loans, innovation capacity, company spending on R\&D, the availability of the latest technologies, and university-industry R\&D collaborations. As we discussed in the previous sections, these results can be validated with respect to the released reports.

As a suggestion for future research, the fuzzy theory-based cumulative belief degrees approach (Kabak and Ruan, 2011) could be applied to reveal the relationships among the indicators with fuzzy linguistic terms. This analysis will lead to a detailed investigation of policy making. Additionally, using the same methodology, other leading industries, such as machinery, iron and steel can be analysed for any country, and useful suggestions can be provided to the policy makers. Moreover, the $\mathrm{BCN}$ developed to analyse the competitiveness of the automotive industry can be refined further using the data mining techniques proposed by $\mathrm{Wu}$ et al. (2012a) in addition to the judgements of experts. Thus, the proposed methodology can be applied to any industry operating in any country.

\section{Acknowledgments}

This research is supported by the Turkish Federation of Industrial Associations (SEDEFED), the TÜSİAD Sabanci University Competitiveness Forum (REF), and the Turkish Automotive Manufacturers Association (OSD). We also thank three anonymous referees who have provided invaluable suggestions to improve the presentation of our research.

\section{References}

Ackermann, F. (2012). Problem structuring methods 'in the Dock': Arguing the case for Soft OR. European Journal of Operational Research, 219(3), 652-658.

Aktas, E., Ulengin, F., \& Onsel Sahin, S. (2007). A decision support system to improve the efficiency of resource allocation in healthcare management. Socio-Economic Planning Sciences, 41(2), 130-146.

Anderson, R.D., \& Vastag, G. (2004). Causal modeling alternatives in operations research: Overview and application. European Journal of Operational Research, 156, 92-109. 
Artto, E. W. (1987). Relative total costs-an approach to competitiveness measurement of industries. Management International Review, 27, 47-58.

Baesens, B., Verstraeten, G., Poel, D.V., Petersen, M.E., Kenhove, P.V., \& Vanthiene, J. (2004). Bayesian Network Classifiers for identifying the slope of the customer lifecycle of long-life customers. European Journal of Operational Research, 156, 508-523.

Barnes, J., \& Morris, M. (2008). Staying alive in the global automotive industry: what can developing economies learn from South Africa about linking into global automotive value chains? The European Journal of Development Research, 20(1), 31-55.

Bottomley, P. A., \& Doyle, J. R. (2013). Comparing the validity of numerical judgments elicited by direct rating and point allocation: Insights from objectively verifiable perceptual tasks. European Journal of Operational Research, 228(1), 148-157.

Budd, L., \& Hirmis, A. (2004). Conceptual framework for regional competitiveness. Regional Studies, 38(9), 1015-1028.

Castellacci, F. (2008). Innovation and the competitiveness of industries: Comparing the mainstream and the evolutionary approaches. Technological Forecasting \& Social Change, 75, 984-1006.

Cerquides, J., \& Mantaras, R.L. (2005). TAN classifiers Based on Decomposable Distributions. Machine Learning, 59, 323-354.

Cho, D. S. (1998). From national competitiveness to bloc and global competitiveness. Competitiveness Review: An International Business Journal incorporating Journal of Global Competitiveness, 8(1), 11-23.

Choi, S. H., \& Jeon, B. N. (2011). The impact of the macroeconomic environment on merger activity: evidence from US time-series data. Applied Financial Economics, 21(4), 233-249.

Cinicioglu, E. N., Önsel, Ş., \& Ülengin, F. (2012). Competitiveness analysis of automotive industry in Turkey using Bayesian networks. Expert Systems with Applications, 39(12), 10923 -10932 .

Daellenbach, H.G. \& McNickle, D.C. (2005) Management science: Decision making through systems thinking, Palgrave Macmillan, China.

D'Costa, A.P. (1998). An alternative model of development? Co-operation and flexible industrial practices in India. Journal of International Development, 10(3) 301-321.

Dunning, J.H. (1992). The competitive advantage of countries and the activities of transnational corporations. Transnational Corporations, 1, 135-168.

EC (European Commission) (2006). CARS 21 A competitive Automotive regulatory Competitive Automotive Regulatory System for the 21 st century, Final Report.

EC (European Commission) (2010). CARS 21, Mid-term review high level conferenceconclusions and report, http://ec.europa.eu/enterprise/sectors/automotive/files/pagesbackground/competitiveness/cars 21_mtr_report_en.pdf, date accessed: November 2010.

EC (European Commission) (2012). CARS 2020: for a strong, competitive and sustainable European car industry, http://ec.europa.eu/enterprise/newsroom/cf/itemdetail.cfm?item_id=6267\&lang=fr, date accessed: November 2012. 
Edwards, L., \& Golub, S.S. (2004). South Africa's International Cost Competitiveness and Exports in Manufacturing. World Development, 32, 1323-1339.

Fauss, E., Gorman, M. E., \& Swami, N. (2009). Using expert elicitation to prioritize resource allocation for risk identification for nanosilver. The Journal of Law, Medicine \& Ethics, 37(4), 770-780.

Guan, J. C., Yam, R.C.M., Mok, C.M., \& Ma, N. (2006). A study of the relationship between competitiveness and technological innovation capability based on DEA models. European Journal of Operational Research, 170, 971-986.

Häger, D., \& Andersen, L. B. (2010). A knowledge based approach to loss severity assessment in financial institutions using Bayesian networks and loss determinants. European Journal of Operational Research, 207(3), 1635-1644.

Hamalainen, T.J. (2003). National Competitiveness and Economic Growth. Gloucestershire: Edward Elgar Publishing Limited

Hruschka, E.R. Jr., \& Ebecken, N.F.F. (2007). Towards efficient variables ordering for Bayesian networks classifier. Data \& Knowledge Engineering, 63, 258-269.

IMD (Institute for Management Development) (2011), IMD World Competitiveness Yearbook http://www.imd.org/research/publications/wcy/index.cfm, 23.11.2012, 2012.

Kabak, Ö., \& Ruan, D. (2011) A cumulative belief degree-based approach for missing values in nuclear safeguards evaluation. IEEE Transactions on Knowledge and Data Engineering, $23,1441-1454$

Kao, C., Wu, W.-Y., Hsieh, W.-J., Wang, T.-Y., Lin, C., \& Chen, L.-H. (2008) Measuring the national competitiveness of Southeast Asian countries. European Journal of Operational Research, 187(2), 613-628

Keys, P.(2007) Developing a design science for the use of problem structuring methods, Systemic Practice and Action Research, 20, 333-349

Korb K.B., \& Nicholson A.E. (2011) Bayesian Artificial Intelligence. CRC Press, Taylor and Francis Group, UK

Laosirihongthong, T., \& Dangayach, G.S. (2005). A comparative study of implementation of manufacturing strategies in Thai and Indian automotive manufacturing companies. Journal of Manufacturing Systems, 24, 2005.

Lauria, E.J.M., \& Duchessi, P.J. (2007). A Methodology for developing Bayesian networks: An application to information technology (IT) implementation. European Journal of Operational Research, 179, 234-252.

Lin, X., \& Wu, G. (2011). Technological capability building in the automotive industry: Comparing China with South Korea. Asia Pacific and Globalization Review, 1(1), 1-15.

Lipovatz, D., Mandaraka, M., \& Mourelatos, A. (2000). Multivariate analysis for the assessment of factors affecting industrial competitiveness: The case of Greek food and beverage industries. Applied Stochastic Models in Business and Industry, 16(2), 85-98.

Liu, P.-L., Chen, W.-C., \& Tsai, C.H. (2004). An empirical study on the correlation between knowledge management capability and competitiveness in Taiwan's industries. Technovation, 24, 971-977.

Madslien, J. (2012). Ford cutting 1400 jobs in the UK - BBC. Retrieved May 16, 2013, from http://www.bbc.co.uk/news/business-20083272. 
Mingers, J., \& White, L. (2010). A review of the recent contribution of systems thinking to operational research and management science. European Journal of Operational

Research, 207(3), 1147-1161.

Mishra, S., Kemmerer, B., \& Shenoy P. (2001). Managing venture capital investment decisions: a knowledge-based approach, Working Paper, School of Business, University of Kansas.

Morgan, K. (2005). Development of a preliminary framework for informing the risk analysis and risk management of nanoparticles. Risk Analysis, 25(6), 1621-1635.

Nadkarni, S., \& Shenoy, P. (2004). A causal mapping approach to constructing Bayesian networks. Decision Support Systems, 38, 259-281.

Naim, P. (2008) Conclusions, In Pourret, O., Naim, P. Marcot, B. (Eds.), Bayesian networks: A practical guide to applications Bayesian networks (pp. 377384) Cornwall: John Wiley and Sons.

Nicholson, A., Twardy, C.R., Korb, K.B., \& Hope, L.R. (2008) Decision support for clinical cardiovascular risk assessment.

Niewenhuis, P., \& Wells, P. E. (Eds.). (2003). The automotive industry and the environment: $A$ technical, business and social future. CRC Press.

OICA (2010) 2010 Production statistics, http://oica.net/category/production-statistics/2010statistics/

Onisko, A. (2008) Medical diagnosis. In Pourret, O., Naim, P. Marcot, B. (Eds.), Bayesian networks: A practical guide to applications bayesian networks (pp. 15-32) Cornwall: John Wiley and Sons.

Oral, M., \& Reisman, A. (1988). Measuring industrial competitiveness. Industrial Marketing Management, 17 (3), 263-272.

Oral, M., Cinar, U., \& Chabchoub, H. (1999). Linking industrial competitiveness and productivity at the firm level. European Journal of Operational Research, 118(2), 271-7.

Porter, M.E. (1990). The competitive advantage of nations. New York: Free Press.

Roessner, J.D., Porter, A.L., Newman, N., \& Cauffiel, D. (1996). Anticipating the future hightech competitiveness of nations: indicators for twenty-eight countries. Technological Forecasting and Social Change, 51, 133-149.

Rowe, G., \& Wright, G. (2011). The Delphi technique : Past, present, and future prospectsIntroduction to the special issue. Technological Forecasting and Social Change, 78, 14871490.

Şahin, A.E., (2001) Delphi technique and its uses in educational research, Hacettepe Üniversitesi Eğitim Fakültesi Dergisi, 20, 215 - 220.

Sala-i-Martin, X., Bilbao-Osorio, B., Blanke, J., Crotti, R., Hanouz, M.D., Geiger, T., \& Ko C. (2012) The Global Competitiveness Index 2012-2013: Strengthening Recovery by Raising Productivity, in World Economic Forum, The Global Competitiveness Report 2012-2013, pp. $3-48$

Simona, G.-L., \& Axèle, G. (2012). Knowledge transfer from TNCs and upgrading of domestic firms: The Polish automotive sector, World Development, 40, 4, 796-807.

Sirikrai, S.B., \& Tang, J.C.S. (2006). Industrial competitiveness analysis: Using the analytic hierarchy process. Journal of High Technology Management Research, 17, 71-83. 
SOP (Turkish State Planning Organization) (2006) The Ninth Development Plan (2007-2013), Report of Automotive Industry Special Working Group, Ankara, Turkey.

Tcha, M.J., \& Kuriyama, T. (2003). Protection policy under economies of scale - the welfare effects of tariffs on the Australian automotive industry. Journal of Policy Modeling, 25, 655672.

TEMIT (Republic of Turkey Ministry of Industry and Trade) (2012), Turkish Automotive Industry Strategy Document (2012), Ankara.

TRMD (Republic of Turkey Ministry of Development) (2012). Medium Term Plan 20132015, Ankara.

TRMSIT (Republic of Turkey Ministry of Science, Industry, and Technology) (2012).

Turkish Industry Strategy Document 2011-2014 (in Turkish), Ankara.

Ulengin F., Önsel Ş., Aktaş E., \& Kabak, Ö. (2010) Competitiveness Strength Report Automotive Industry (in Turkish), REF-SEDEFED, Istanbul.

Wad, P. (2008). The development of automotive parts suppliers in Korea and Malaysia: A global value chain perspective. Asia Pacific Business Review, 14(1), 1 47-64.

Wang, T.-Y., Chien, S.C., \& Kao, C. (2007). The role of technology development in national competitiveness - Evidence from Southeast Asian countries. Technological Forecasting \& Social Change, 74, 1357-1373.

WEF (World Economic Forum) (2012), The Global Competitiveness Report 2012-2013, Switzerland.

Williams, B.J., \& Cole, B. (2013). Mining monitored data for decision-making with a Bayesian network model. Ecological modelling, 249, 26-36.

Williamson, R. (2001). Exchange rate exposure and competition: evidence from the automotive industry. Journal of Financial Economics, 59, 441-475.

Wu, W.W.(2010). Linking Bayesian networks and PLS path modeling for causal analysis. Expert Systems with Applications, 37, 134-139.

Wu, W.W., Lan, L. W., \& Lee, Y. T. (2012). Exploring the critical pillars and causal relations within the NRI: An innovative approach. European Journal of Operational Research, 218, 230-238.

Wu, W.W., Lan, W.L., \& Lee, Y.T. (2012). Critiquing the World Economic Forum's concept of destination competitiveness: A further analysis. Tourism Management Perspectives, 4, 198206.

Zanakis, S.H., \& Becerra-Fernandez, I. (2005). Competitiveness of nations: A knowledge discovery examination. European Journal of Operational Research, 166, 185-211. 


\section{Highlights}

- Problem structuring for the competitiveness of the automotive industry

- Analysis of competitiveness of the automotive industry using Bayesian Causal Networks

- A decision support methodology to policy makers of the automotive industry.

- Sensitivity analysis using Bayesian Causal Networks

- Improving the competitiveness of automotive industry based on national competitiveness 